\title{
IoT Based Smart Agriculture Aid System using Raspberry Pi
}

\author{
Priyanka Bhardwaj, Adarsh Srivastava, Abhishek Kumar Pandey, Abhishek Singh, Bhartendu Tripathi
}

\begin{abstract}
Agriculture is the worldwide one of the most important occupation of human being, nearly about $64 \%$ of total available land on earth is occupied by the agriculture sector, which results in comsuming $85 \%$ of fresh water. This percentage of water consumption increases every year due to globalization and fulfilling human needs. Every country face challenge to sustain the fresh food requirement and reducing the farm water consumption. Currently, the farmers look over at irrigation methods manually and irrigate their area on a constant routine period. These process acquire large amount of water and as a result water is wasted. Therefore, Raspberry Pi communication system is preferred because of its easy operation, maintenance and cost. This prototype is automated which will irrigate the crop by detecting the moisture content and also will keep an eye on the soil quality.

Keywords: Every Country Face Challenge to Sustain the Fresh Food Requirement and Reducing the Farm Water Consumption. Currently
\end{abstract}

\section{INTRODUCTION}

In the current scenario, a major problem that world is facing is undergoing groundwater table and water is needed in large quantity in agriculture. So there is a need of a sustainable system. At present, everywhere irrigation is performed manually. The enhancement in the science sector as removed lots of things that previously looked impossible. In the current situation, the advancement of mobiles, laptops, automobiles, "smart" science and technology has expanded the market and has set up new standards. This technology Internet of things provides power to the specific interrelationship among several entities, materials, and features based on the net and this technology will help the peoples to perform there work easily and smartly. Smart agriculture is an innovative scenario where many innovators are taking interest and for a long time, it is expanding day after day.

Manuscript received on June 04, 2021.

Revised Manuscript received on June 15, 2021.

Manuscript published on June 30, 2021.

* Correspondence Author

Dr. Priyanka Bhardwaj, Department of Electronics and Communication Engineering, ABES Engineering College Affiliated to AKTU Ghaziabad (U.P), India. E-mail: priyanka.bhardwaj@abes.ac.in

Adarsh Srivastava*, Department of Electronics and Communication Engineering, ABES Engineering College Affiliated to AKTU, Ghaziabad (U.P), India. E-mail: adarsh.17bec1095@abes.ac.in

Abhishek Kumar Pandey, Department of Electronics and Communication Engineering, ABES Engineering College Affiliated to AKTU, Ghaziabad (U.P), India. E-mail: abhiehek.17bec1085@abes.ac.in

Abhishek Singh, Department of Electronics and Communication Engineering, ABES Engineering College Affiliated to AKTU, Ghaziabad (U.P), India. E-mail: abhishek.17bec1111@abes.ac.in

Bhartendu Tripathi, Department of Electronics and Communication (U.P) India. E-mail: bhartendu.17bec1155@abes.ac.in

(C) The Authors. Published by Blue Eyes Intelligence Engineering and Sciences Publication (BEIESP). This is an open access article under the CC BY-NC-ND license (http://creativecommons.org/licenses/by-nc-nd/4.0/) Engineering, ABES Engineering College Affiliated to AKTU, Ghaziabad

Pressure on the distribution of water systems has increased a bit and also importance of management of water has increased due to the sustainability of agriculture farming. In real, the main motive of smart agriculture is reducing human efforts, less use of water, and avoid more power consumption.. Crops also depend on the type of soil and its toxicity. A soil with a good $\mathrm{pH}$ value will result in the proper growth of plants. Regular maintenance is required for the best quality of soil. A smart agricultural aid system works automatically and uses different sensors along with rain sensor to timely water the crops without human interference and also will test the soil quality using a $\mathrm{pH}$ sensor. So the main motive is to design a accurate system, check the nature of the soil that provides all the proper nutrients. The Temperature is also kept in mind so that the temperature around the crops can be examined as the crop temperature is also very sensitive.

\section{LITERATURE REVIEW}

[1] Proposed a paper in which the sensors having humidity and soil moisture sensors are placed within the root area of the plant. supported the sensed values the microcontroller is employed to regulate the availability of water to the sector. this technique is not helpful to the farmer as it does not tells about the status of sector.

[2] a paper was proposed during which soil parameters like $\mathrm{pH}$, humidity,and temperature are measured so as to get high outcome from the soil. This process is fully automated which switches the motor pump ON/OFF as per the content of moisture in the soil.

[3] Proposed a paper in which photo voltaic cells are used to receive power. Electricity is not required in this system. The soil moisture sensor is used and supported the sensed values PIC microcontroller is employed to ON/OFF the motor pump. meteorology isn't included in this system.

[4] Proposed a system in which drip irrigation using IOT is used .In this humidity, temperature, $\mathrm{pH}$ sensors, etc are used. A computer is used for the updation purpose of irrigation. Internet is needed for accessing the field condition.

[5] Proposed an irrigation system based on Iot which uses network of wireless sensors containing different sensors to measure different components of soil. The system is controlled remotely by web providing a web interface. It has a limitations that weather monitoring is not available.

[6] Proposed a prototype that takes on sensor information, triggers the actuators and transmits data to the server. Its consists of photovoltaic panels and has a both side communication link available based on a mobile internet interface that helps in inspection of data and irrigation time is scheduled from web server.

Published By:

Blue Eyes Intelligence Engineering and Sciences Publication

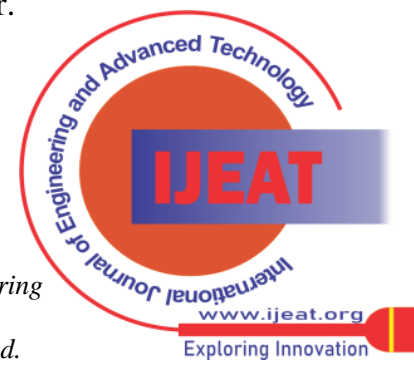




\section{PROBLEM STATEMENT}

The major problem that farmers face is irregular distribution of water in the field. Crops do not get the required nutrients because of poor soil quality which results in there improper growth.

\section{PROPOSED SOLUTION}

We are designing an IOT based Smart Agricultural Aid System which is based on Raspberry Pi that operate automatically by sensing the moisture content and humidity of the soil. It will also study the rainfall pattern in the particular region by using the Rain Sensor and will switch ON/OFF the pump using relay without human intervention and hence result in saving of water. Soil quality will be maintained with the help of $\mathrm{pH}$ sensor which will result in proper enrichment of crops.

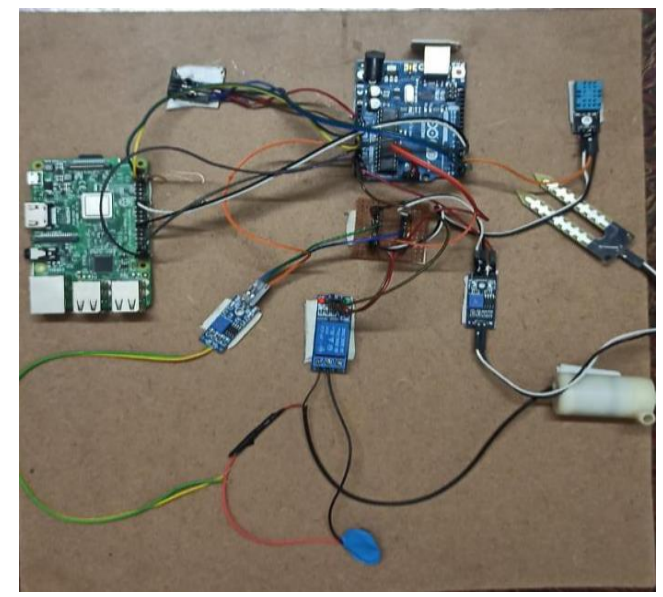

Fig 1.Circuit Diagram

In this project, we learn about IoT Based Smart Agricultural Aid System using Raspberry Pi. Agriculture sector plays a huge impact in the enhancement of countries which totally depend on agriculture. The issues related to agriculture result in declining the progress of the country. The best solution to this problem is sensible agriculture by updating the current old methods or practice of agriculture.

So the tactic is making our agriculture more advance using different automation techniques and IoT based technologies. With the help of Internet of Things (IoT) we can have proper crop growth monitoring and selection, automatic irrigation, etc. A Raspberry Pi Based Smart Agriculture Aid System is proposed to modernize as well as improve the productivity of the crop in the field.

In our project, We are making IoT based Smart Agriculture Aid System by using some advance sensors which we can get easily from market. A Capacitive- Soil Moisture Sensor to required to measure moisture content present throughout the soil. A DHT-11 Humidity Temperature Sensor to measure Air Temperature and Humidity respectively. A Rain Sensor will be used which will turn off the motor pump in case of rainfall.

A $\mathrm{pH}$ sensor will be used to detect the toxicity of the soil. It will help in deciding the farmers that whether the crops are getting proper nutrients or not. A Power relay of $5 \mathrm{~V}$ will control the pump. So, whenever a low amount of moisture is detected in the soil, the motor automatically starts working, and hence the irrigation is completed automatically. When the soil becomes wet, automatically motor turns off. These all process can be monitored remotely through Thing speak Server online from everywhere..

\section{Internet of Things (IoT)}

The Internet of things (IoT) consists of number of sensors and modules which help in making the things automated so that they does not involve human for operating them. It consists of various hardware and software combination together to make things working automatically

The IoT uses sensing devices to sense changes and control things remotely, which helps in leading direct integration of the physical world existence into a computerbased system which leads to provide more efficiency, accuracy as well as economic benefit additionally to reduce involvement of human being. At time when IoT is set up with sensors, the technology a glimpse of compute based systems, which also includes technologies like smart grids, smart highways, smart homes, etc.

There are some places where human reach is complex. These areas are automated with the help of IoT resulting in lowering human effort as well as cost.

\section{Working Flowchart:}

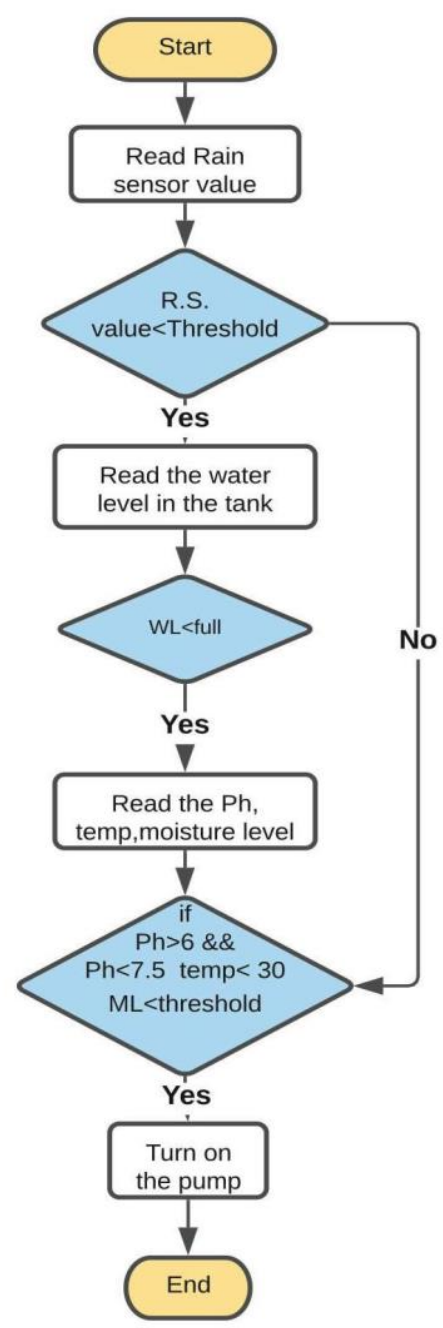

[Block diagram of the proposed prototype]

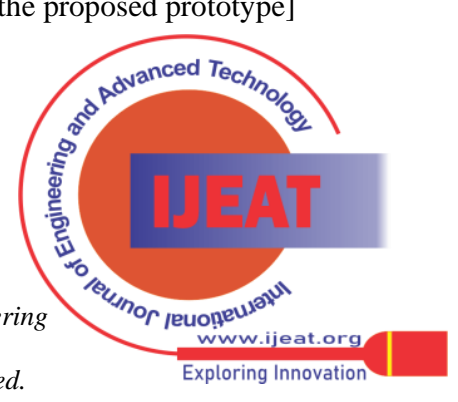




\section{Component Description}

In this project, we use different types of sensors and various other components. These are:

\section{Capacitive Soil Moisture Sensor}

It measures soil moisture level by capacitive sensing, means capacitance is changing according to the water content available within the soil. The received capacitance is changed into volt level i.e. from $1.3 \mathrm{~V}$ to $3.2 \mathrm{~V}$ at most. The surplus of Capacitive Soil Moisture Sensor is , they are made from a corrosive- and resistant material which gives it more service life. It also supports a 3-pin sensing interface.

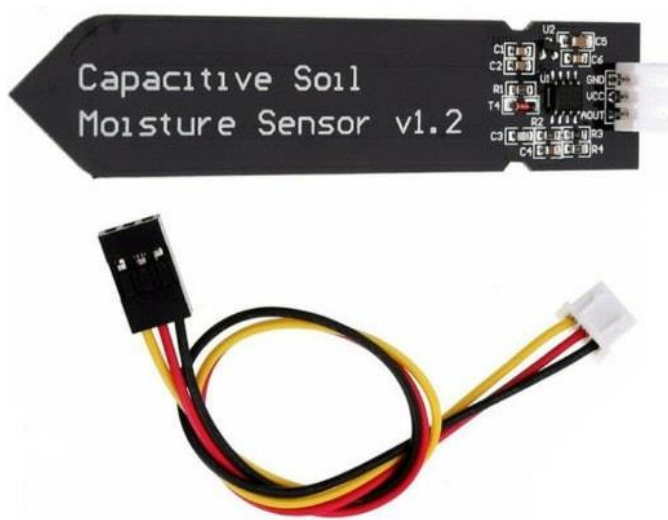

Fig 2. Capacitive Soil Moisture Sensor

\section{Humidity Temperature Sensor}

It is a simple digital humidity and temperature sensor. We'll use this sensor to live the air temperature as well as humidity. It makes use of a humidity sensor to live the encompassing wind and gives out a digital signal on the output pin. It's not very complex but requires careful attention to grab the data. It has a limitation that through this sensor we will get newer data from it on every 2 seconds, so when we use the library, sensor readings are frequently up to 2 seconds old.
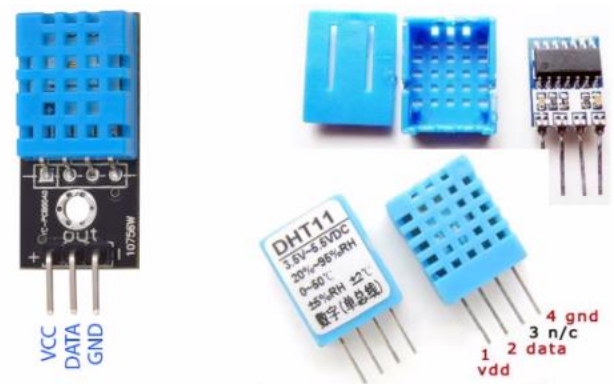

Fig 3. DHT11 Humidity Temperature Sensor

\section{Micro Submersible water pump (3-6V DC)}

A DC 3-6 V Mini Submersible based pump is a lowcost, limited size Submersible Pump Motor that may be operated with a 2.5 - 5V power supply. It has the capacity to take 140 liters per hour and takes very low current consumption of around $220 \mathrm{~mA}$. The tube pipe is just connected to the motor outlet, drowned in water, and give power to it.

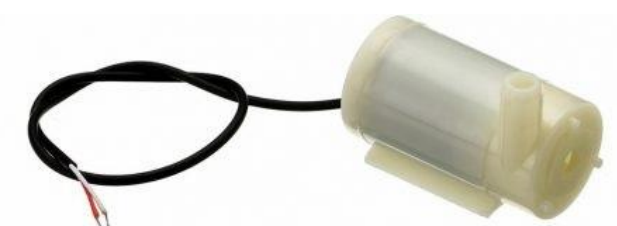

Fig 4. Micro Submersible water pump

\section{4. pH Sensor}

A pH sensor weather the water is alkaline or acidic with a value between $0-14$ on a scale. As the $\mathrm{pH}$ value goes down 7 , the water will become more acidic. $\mathrm{pH}$ value above 7 shows alkalinity . Each type of $\mathrm{pH}$ sensor performs it works differently to measure the quality of the water.

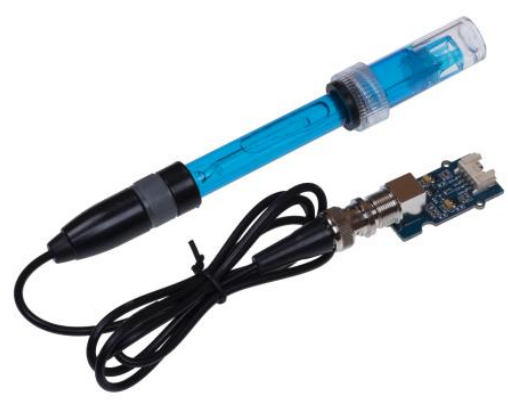

Fig 5. pH Sensor

\section{Rain Sensor}

As per the name, a rain sensor is a switching device which turn $\mathrm{ON}$ by rainfall. It has two important applications. First is a water storing device which is attached to the irrigation system that results in turning OFF system when rainfall occurs. The second is a device that is employed to guard the inner side of an automobile from rainfall and to provide support to the windscreen wipers which are automated.

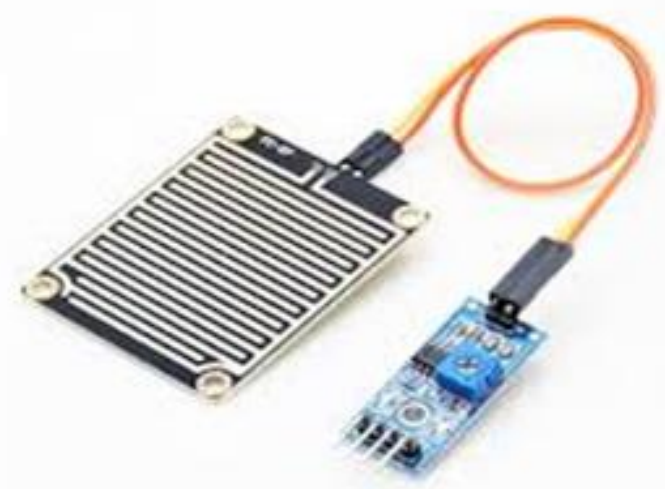

Fig 6. Rain Sensor

\section{Raspberry Pi 3}

Raspberry Pi 3 is a development board in the PI series. It can be considered as a single-board computer that works on LINUX operating system. The board not only has tons of features it also has terrific processing speed making it suitable for advanced applications.

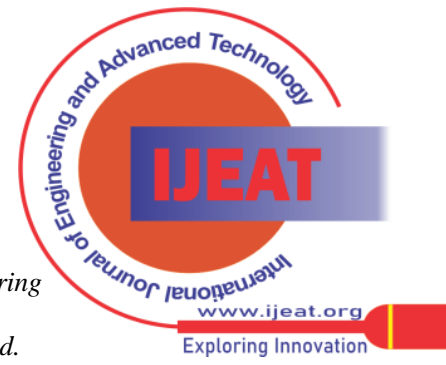




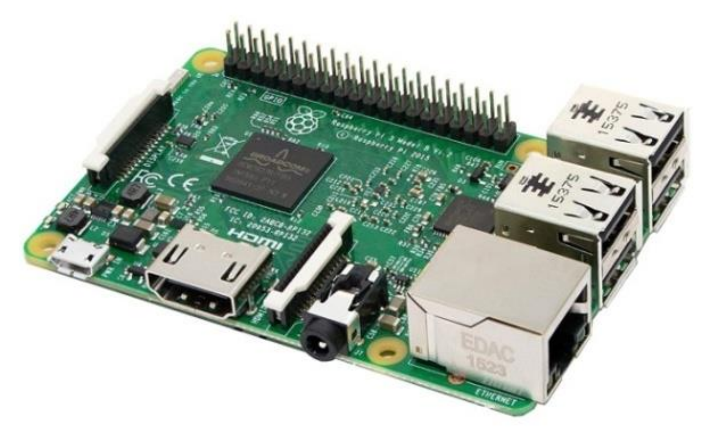

Fig 7. Raspberry Pi 3

\section{RESULTS}

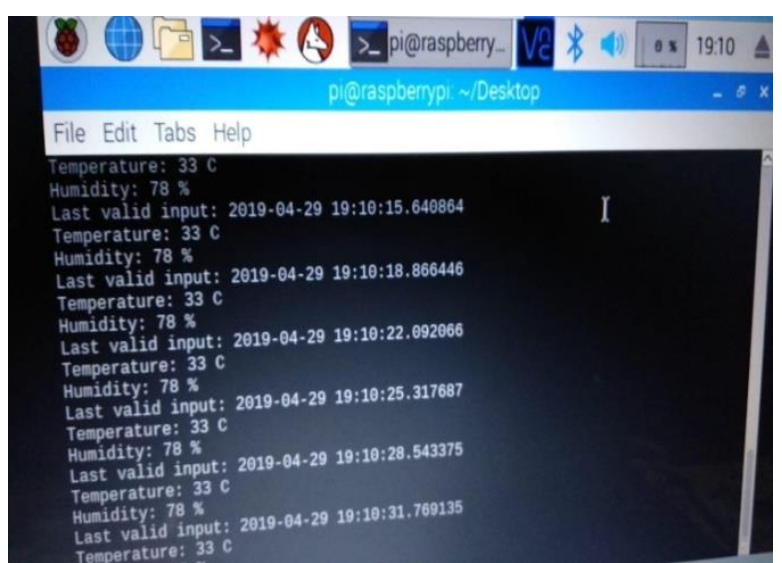

Fig 8.Temperature and Humidity Readings

The temperature and humidity of the surrounding area was analysed using the DHT11 sensor and according to that the water was supplied to the plant. When a certain level of humidity was there the pump was kept 'OFF' while with less humidity the pump was turned ' $\mathrm{ON}$ '.

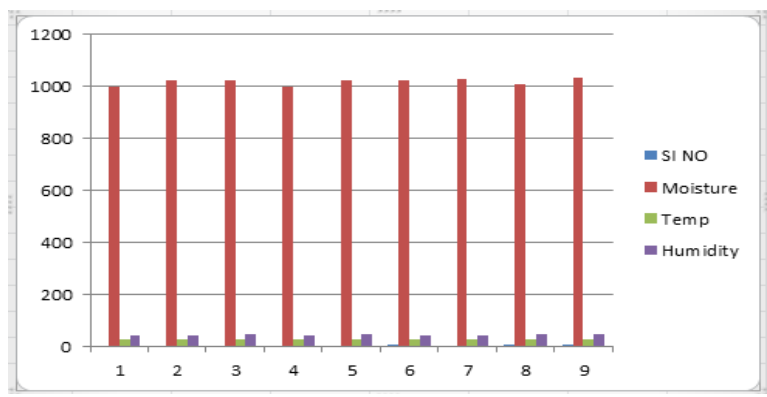

Fig 9.Sensor values updation in chart

\begin{tabular}{|c|c|c|}
\hline Time stamp & Temperature Humidity \\
\hline 2015-12-13 21:16:06 & 22 & 45 \\
\hline 2015-12-13 21:11:06 & 22 & 40 \\
\hline 2015-12-13 21:06:06 & 22 & 45 \\
\hline $2015-12-1320: 50: 32$ & 21 & 45 \\
\hline $2015-12-1320: 45: 32$ & 21 & 45 \\
\hline $2015-12-1320: 40: 32$ & 20 & 40 \\
\hline $2015-12-1320: 35: 32$ & 21 & 45 \\
\hline $2015-12-1320: 30: 31$ & 22 & 45 \\
\hline $2015-12-1320: 25: 31$ & 21 & 45 \\
\hline
\end{tabular}

Fig 10.T/H Sensor Data's Updation.

\section{CONCLUSION}

The advancement of agriculture field networking technology is required very much for agricultural development, but also a crucial sign of the far level of agricultural development. It'll be the longer-term plan of agricultural development

After building the smart agricultural aid system hardware and analyzing and researching the network hierarchy features, functionality and the corresponding software architecture of precision irrigation systems and detecting soil nature, applying the internet of things to agricultural production has a great impact on making the efficient use of water resources which are available and also ensuring the efficiency as well as accuracy with stability of agricultural production.

\section{FUTURE SCOPE}

As technology is developing day by day, so with more features develop in IoT these systems can be made efficient ,more stable, much faster with accuracy and will cost less. In the coming future, this system can be and must be adopted by agricultural farmers.

\section{REFERENCES}

1. Archana and Priya, "Design and Implementation of Automatic Plant Watering System" presented at International Journal of Advanced Engineering and Global technology, vol-04, Issue-01, Jan-2016...

2. Sonali.D.Gainward and Dinesh.V.Rojatkar, "Soil Parameters Monitoring with Automatic Irrigation System" presented at International Journal of Science, Engineering and Technology Research (IJSETR), vol-04, Issue 11, Nov 2015.

3. V.R.Balaji and M.Sudha, "Solar Powered Auto Irrigation System" presented at International Journal of Emerging Technology in Computer Science and Electronics (IJETCSE), vol20 Issue-2, Feb2016

4. G.Parameswaran and K.Sivaprasath, "Arduino Based Smart Drip Irrigation System Using IOT" presented at International Journal of Engineering Science and Computing (IJESC), May 2016.

5. S.Reshma and B.A.Sarath Manohar Babu, "Internet of things Based Automatic Irrigation System using Wireless Sensor Networks" presented at International Journal and Magazine of Engineering, Technology, Management and Research, vol-03, Issue-09, Sep2016.

6. Joaquin Gutierrez and Juan Francisco, "Automated Irrigation System using a Wireless Sensor Network and GPRS Module" presented at IEEE Transactions on Instrumentation and Measurement, 2013.

7. Ning Wang, Naiqian Zhang, Maohua Wang, "Wireless sensors in agriculture and food industry-Recent development and future perspective", published inComputers and Electronics in Agriculture 2006.

8. Pepper Agro, "M-Drip Kit" Internet: www.pepperagro.i/mdripkitmanual.htmlSiuli Roy, SomprakashBandyopadhyay, "A Test-bed on Real-time Monitoring of Agricultural Parameters using Wireless Sensor Networks for Precision Agriculture" 2007.

9. Yiming Zhou, Xianglong Yang, Liren Wang, Yibin Ying, A wireless design of a low-cost irrigation system using ZigBee technology, International Conference on Networks Security, Wireless Communications and Trusted Computing, IEEE 2009.

10. Zhang xihai, Zhang changli Fang junlong. Smart Sensor Nodes for Wireless Soil Temperature Monitoring Systems in Precision Agriculture 2009.

11. R.Suresh, S.Gopinath, K.Govindaraju, T.Devika, N.SuthanthiraVanitha, "GSM based Automated Irrigation Control using Raingun Irrigation System”, International Journal of Advanced Research in Computer and Communication Engineering Vol. 3, Issue 2, February 2014. 
12. Pavithra D.S, M. S .Srinath, "GSM based Automatic Irrigation Control System for Efficient Use of Resources and Crop Planning by Using an AndroidMobile", IOSR Journal of Mechanical and Civil Engineering (IOSR-JMCE) Vol 11, Issue I, Jul-Aug 2014, pp 49-55.

13. Laxmi Shahabadi, NandiniPatil, Nikita. M, Shruti. J, Smitha. P Swati. C, and Software Engineering, Volume4, Issue 7, July 2014. "Irrigation ControlSystem Using Android and GSM for Efficient Use of Water and Power", International Journal of Advanced Research in Computer Science

14. Shiraz Pasha B.R., Dr. B Yogesha, "Microcontroller Based Automated Irrigation System", The International Journal Of Engineering And Science (IJES), Volume3, Issue 7, pp 06-09, June 2014.

15. S. R. Kumbhar, Arjun P. Ghatule, "Microcontroller based Controlled Irrigation System for Plantation", Proceedings of the International MultiConference of Engineers and Computer Scientists 2013VolumeII, March 2013.

16. Yunseop (James) Kim, Member, IEEE, Robert G. Evans, and William M. Iversen, "Remote Sensing and Control of an Irrigation System Using a Distributed Wireless Sensor Network", IEEE TRANSACTIONS ON INSTRUMENTATION AND MEASUREMENT, Volume 57, Number 7, JULY 2008.

17. Venkata Naga RohitGunturi, "Microcontroller Based Automatic Plant Irrigation System", International Journal of Advancements in Research \& Technology, Volume 2, Issue4, April-2

\section{AUTHORS PROFILE}

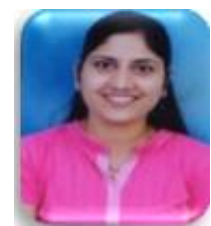

Dr. Priyanka Bhardwaj, has done her Ph.D and M.Tech from IIT Delhi and B.Tech Hons. as university ranker from UPTU. She is currently working as Associate Professor in ECE department with ABES Engineering College and leading Research and Innovation group of her department. She has got three patents and published more than 30 research articles in reputed Journals and Conferences. She has more than 13 years of academic and research experience and is reviewer of various Journals. Her area of interest is Optical Wireless, Nano photonics and Plasmonics. She has recently been felicitated by AICTE for her Excellence in Teaching and Research.

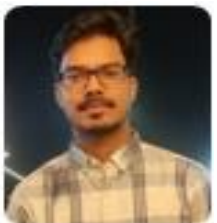

Adarsh Srivastava, is currently perusing B.Tech final year from ABES Engineering College in Electronics and Communication Engineering. He has completed his $10+2$ from a CBSE school with good academic score. He has a good knowledge in the field of embedded systems, Internet of Things and Digital Electronics. His area of interests is Control Systems and Embedded System. He has provided support to the production and design team, developed the electronic hardware and their specification.

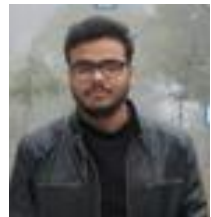

Abhishek Kumar Pandey, is perusing B.tech from ABES Engineering College in Electronics and Communication Engineering. $\mathrm{He}$ is an innovative Electronics Engineer with a sound knowledge in telecommunications and electronics devices. He has knowledge of Safety Case, Major Accidents and Hazards. He has analytical skills to follow logic of electronic circuits and interface with software

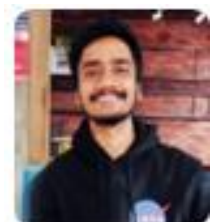

Abhishek Singh, is perusing B.tech from ABES Engineering College in Electronics and Communication Engineering .He is an innovative Electronics Engineer with extensive experience in telecommunications and electronics devices. He is adept at routing embedded circuits, gauging resistance devices and designing effective circuit boards. He specializes in small, handheld electronics.

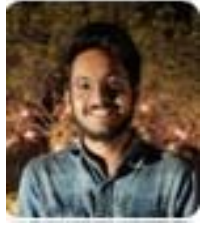

Bhartendu Tripathi, is perusing B.tech from ABES Engineering College in Electronics and Communication Engineering. He is strong in design and integration with intuitive problem-solving skills. He is passionate about implementing and launching new projects. He has the ability to translate business requirements into technical solutions.

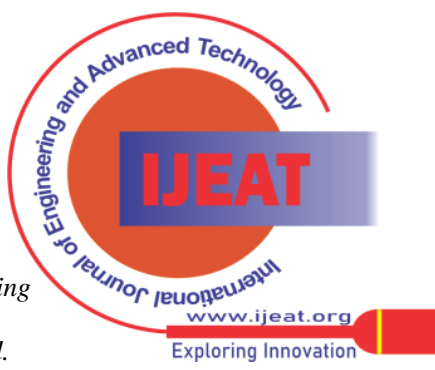

